\title{
In situ freeze-capturing of fracture water using cryogenic coring
}

9

11

$12{ }^{1}$ Earth Sciences Division, Lawrence Berkeley National Laboratory, Berkeley, CA 94720

$13{ }^{2}$ Department of Material Science and Mineral Engineering, University of California, Berkeley,

15

Short Communication

17

January 2004 


\section{Abstract} uses liquid nitrogen as the drilling fluid, which can freeze the fracture water in place while coring. Laboratory experiments are conducted to demonstrate that water in an unsaturated

33 fracture can be frozen and collected using cryogenic coring. 


\section{Introduction}

(a)

and contaminant transport. Water sampling in the saturated zone is often performed by pumping water out of wells, while water in unsaturated unconsolidated soils is generally extracted for sampling using a suction lysimeter. Sampling in situ water from unsaturated fractures in lowmoisture environments remains a challenge, however, and has not to date been successful because flow typically occurs along preferential flow paths (e.g. Nicholl et al., 1994; Su et al., 1999; Wang and Bodvarsson, 2003) that are difficult to sample using conventional methods. Characterization of water and contaminants in unsaturated fractured rock is important for a number of applications, including remediation of contaminated sites, storage of high-level nuclear waste at Yucca Mountain, Nevada, and recharge in arid environments.

In situ water from soils and rock is also often obtained by removing pore water directly from core samples. In unsaturated fractured rock, pore water from the rock matrix can be extracted from cores, but water in the fractures will likely be displaced or contaminated by the drilling fluid used during coring. For hard rocks, rotary coring is typically used, in which the rotary coring bits (usually made out of diamond or tungsten carbide) are designed to cut away the perimeter material in the borehole while the center material is guided into the core barrel. Nativ et al (1999) used two methods for coring in soft fractured chalk. Spiral-augering was used at shallower depths and rotary crushing with extensive water circulation was used for deeper boreholes and/or massive chalk formations. The second method eliminated the possibility of sampling the vadose zone chalk. 
Cryogenic coring may be a promising method for obtaining in situ water samples from

unsaturated fractured rock. Freezing soil to obtain shallow sediment samples near streams and wetlands has been performed for several decades. The technique has traditionally involved inserting a metal-pointed pipe into the sediment to a depth of about $1 \mathrm{~m}$, and then liquid nitrogen or liquid carbon dioxide is circulated into the pipe (e.g., Walkotten, 1973; Knaus, 1986). The frozen soil adjacent to the pipe is then sampled. Cryogenic coring was also performed in unconsolidated soils by Cavagnaro (1999), using a novel method that was an extension of the cryogenic drilling technique developed by Simon and Cooper (1996). This method uses standard air rotary drilling techniques, but cold nitrogen $\left(\sim 196^{\circ} \mathrm{C}\right)$ rather than ambient air is used as the circulation fluid. During drilling, the cold nitrogen freezes and stabilizes the borehole wall. This method has minimal contamination from external sources since the drilling fluid is liquid nitrogen. The possibility of extracting clean frozen cores with improved quality over cores extracted using traditional methods exists using cryogenic coring. The advantages of the cryogenic coring technique used by Cavagnaro (1999) over the pipe insertion method are that it can be applied to much greater depths and it can be used over a range of media, including fractured rock.

Cavagnaro (1999) examined cryogenic coring in unconsolidated soil, but did not investigate this technique in fractured rock. A possible advantage of using liquid nitrogen while coring in fractured rock is that water in the fractures can be frozen in place, allowing for in situ fracture water collection. The fracture water freezes by conduction with the frozen rock and/or convection with the nitrogen gas. No technique currently exists for collecting in situ water samples in unsaturated fractures. Laboratory tests are presented in this paper to examine the 
81 effectiveness of cryogenic coring as a method for sampling in situ water from unsaturated

82 fractures.

83

\section{Experimental Methods}

Cryogenic coring was performed on a sandstone rock with a single horizontal fracture.

Two $24 \times 12 \times 3.5 \mathrm{~cm}$ sandstone slabs were placed on top of each other to create the fracture and were clamped together on one end of the rock sample (Figure 1). An aperture gradient was created, with the apertures gradually increasing away from the clamp. The aperture ranged from approximately $0.5 \mathrm{~mm}$ to $3 \mathrm{~mm}$. The rock slabs were initially saturated with water before they were assembled. The sides of the sample were left open to the atmosphere to allow for unsaturated conditions in the fracture.

The coring equipment consisted of a pillar-mounted drill press that was converted for coring of soils and rocks (Figure 1). A side entry swivel used in place of a chuck allowed for the introduction of liquid nitrogen into the interior of a one-inch diamond-tip core barrel that was attached to the swivel. A hose connected a cylinder of liquid nitrogen directly to the swivel fitting, and the sandstone rock was placed directly below the core barrel. Coring was performed after the liquid nitrogen had cooled the core barrel, which was evident by the formation of frost on the outer surface of the core barrel. Each core was extracted in approximately 3-4 minutes.

Three experiments were performed to test cryogenic coring as a tool for collecting water in fractured rock. Experiment 1 was conducted where no water was injected into the fracture, but the rock matrix was saturated. Experiments 2 and 3 were conducted with a finite volume of water injected into the fracture before coring. The fracture was nearly saturated with water in 
104 Experiments 2 and 3, but since the sides of the sample were not sealed, some of this water exited 105 the fracture before the rock was cored.

106

107

108

109

110

111

112

113

114

115

116

117

118

119

120

121

\section{Results and Discussion}

In Experiment 1, no water was injected into the fracture, and the core extracted from the matrix had small pieces of frost on the surface, as shown in Figure 2. The frost could be due to condensation from the air or because some of the matrix water was driven out as the sample was cored. No additional evidence of frozen water was observed on the core or on the fracture surfaces. This observation will be used as a baseline to compare with the cores extracted from the other experiments.

Two cores were extracted from the partially saturated fracture in Experiment 2. The first core extracted did not have any evidence of ice on the fracture surfaces and looked similar to the core extracted in Experiment 1. A second core was subsequently extracted adjacent to the first core, and ice was observed on one of the fracture surfaces, as shown in the circled region in Figure 3a. The fracture was opened after the second core was extracted to examine the fracture surface. Ice near the cored areas was observed as well as an unfrozen water film further away from the cored regions where the clamp was located.

To ensure the repeatability of extracting ice from the fracture, Experiment 3 was conducted. The first core extracted in this experiment had ice on the fracture surfaces, as shown in Figure 3b. Condensation had already occurred on the surfaces by the time the photograph was taken. Frost began to form on the core surface shortly after the core was left at room temperature. 
126 This observation indicated that the cores must be stored below freezing temperatures

127 immediately after extraction to minimize condensation. present on the second core. The absence of ice on the core may have resulted from the core being drilled through a region of the partially saturated fracture that contained very little or no water.

131 The lack of water on the core may have also resulted from some of the fracture water being 132 displaced by the liquid nitrogen pressure during coring. Cavagnaro (1999) investigated water

133 movement caused by cold nitrogen gas flowing through a partially saturated sand core and measured water losses up to $20 \%$ at higher water contents. Compared to water in larger apertures, water in smaller apertures is less likely to be displaced by the liquid nitrogen pressure

136 since the water will freeze faster in the smaller apertures. In our experiments, the fracture had an aperture gradient owing to a clamp being placed on one end of the sandstone rock sample.

138 Observation of the fracture surface after the cores were extracted in Experiment 2 indicated that condensation was present in the region with the largest apertures, but little if any ice was present

140 in that part of the fracture. Some ice was observed, however, in the middle region of the fracture 141 where the apertures were smaller.

\section{Potential Applications} freeze and collect in situ water in unsaturated fractures. This technique could have a range of applications for characterizing in situ water and contaminant distributions in fractured porous media. Other currently used coring techniques do not allow for fracture water sampling without 
contaminating the core or displacing the fracture water. In fractured rocks contaminated with non-aqueous phase liquids (NAPLs), traditional coring methods may not be effective for determining NAPL distributions since the NAPL may remobilize or drain during sampling. Cryogenic coring may, however, be a promising tool for extracting undisturbed samples from fractured rocks contaminated with NAPLs. Characterization of water and contaminants in the subsurface can also be difficult because of the heterogeneous conditions, but another advantage of cryogenic coring is that it can be used over a range of media. This technique could also be used for obtaining undisturbed cores for microbial and geochemical analyses. Fracture-matrix processes may also be investigated, since simultaneous sampling of water and contaminants in the fracture and matrix is one of the intrinsic advantages of using cryogenic coring.

One limitation of cryogenic coring is that water in larger apertures may become displaced by the liquid nitrogen pressure. However, the rate of coring can be reduced to allow for more time for the fracture water in the larger apertures to freeze by conduction with the rock. Contamination of the samples by condensation is another challenge, but this can be minimized by keeping the samples in liquid nitrogen after core samples are retrieved.

\section{Acknowledgements}

This work was supported by the Director, Office of Civilian Radioactive Waste Management, U.S. Department of Energy, through Memorandum Purchase Order EA9013MC5X between Bechtel SAIC Company, LLC, and the Ernest Orlando Lawrence Berkeley National Laboratory (Berkeley Lab). The support is provided to Berkeley Lab through 
171 the U.S. Department of Energy Contract No. DE-AC03-76SF00098. The authors would like to

172 thank Rohit Salve and Dan Hawkes for reviews of this manuscript.

173

174

175

176

177

178

179

180

181

182

183

184

185

186

187

188

189

190

191

\section{References}

Cavagnaro, P., The improvement and environmental soil sampling through the application of cryogenic drilling and coring, M.S. Thesis, University of California, Berekeley, 1999.

Knaus, R.M. and D.R. Cahoon. A cryogenic coring device for sampling loose unconsolidated sediments near a water-sediment interface, Journal of Sedimentary Petrology. 60: 622623, 1986.

Nativ, R., E.M. Adar, and A. Becker. Designing a monitoring network for contaminated ground water in fractured chalk, Ground Water. 37(1): 38-47, 1999.

Nicholl, M.J., R.J. Glass, and S.W. Wheatcraft, Gravity-driven infiltration instability in initially dry nonhorizontal fractures, Water Resources Research, 30(9), 2533-2546, 1994.

Simon, R.D. and G.A. Cooper., Cryogenic Drilling - A New Drilling Method For Environmental Remediation, Ground Water Monitoring \& Remediation. 16(3): 79-85, 1996. 
192 Su, G.W., J.T. Geller, K. Pruess, and F. Wen, Experimental studies of water seepage and intermittent flow in unsaturated, rough-walled fractures, Water Resources Research, 35(4), 1019-1037, 1999.

195

196 Walkotten, W.J., A freezing technique for freeze sampling streambed sediments, U.S. Dept of Agriculture, Forrest Service Reserve, PNW-205. Pacific NW Forest Range Exp., Portland, OR, 1973.

199

200 Wang, J.S.Y. and G.S. Bodvarsson, Evolution of the unsaturated zone testing at Yucca Mountain, Journal of Contaminant Hydrology, 62-63:337-360, 2003. 


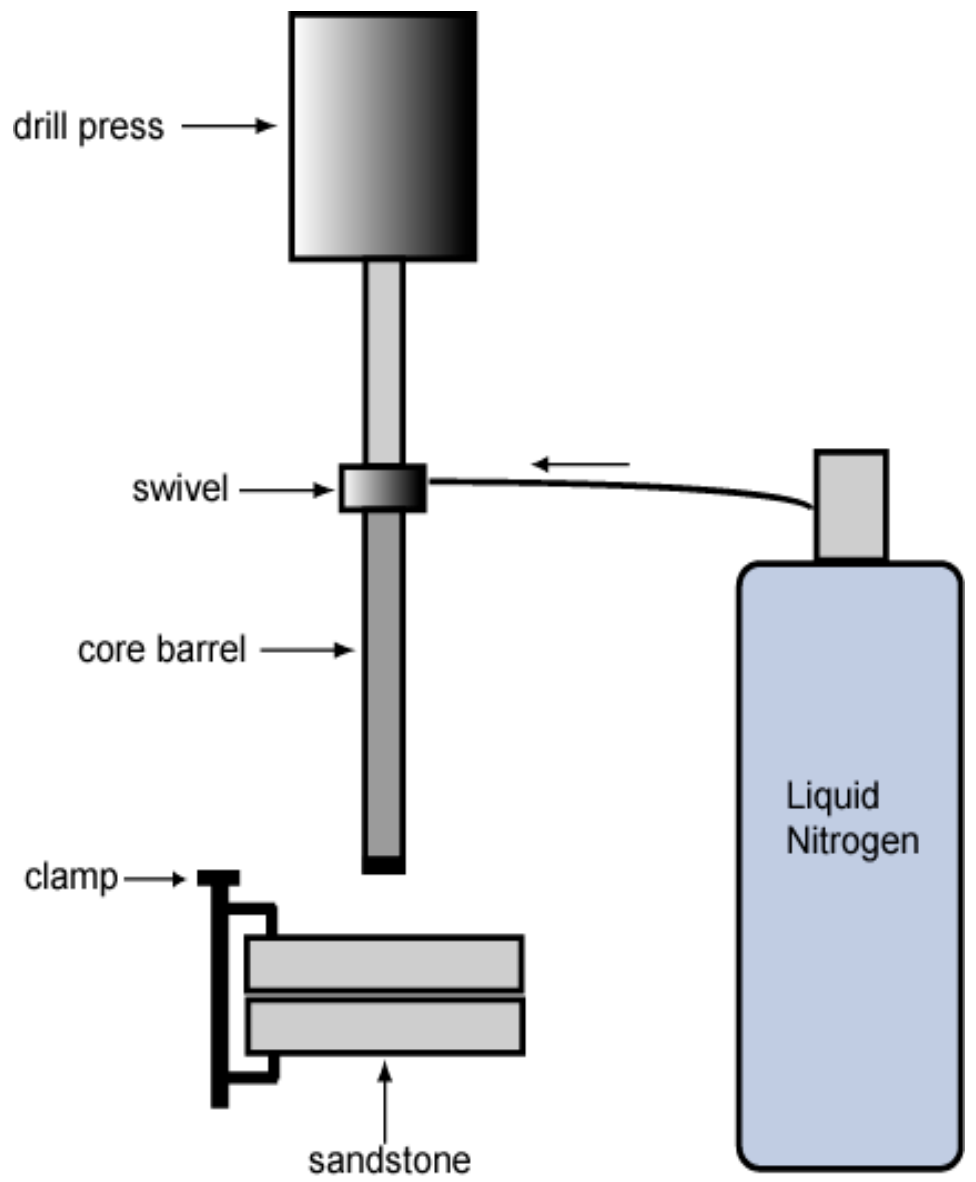

Figure 1. Schematic of the experimental apparatus 


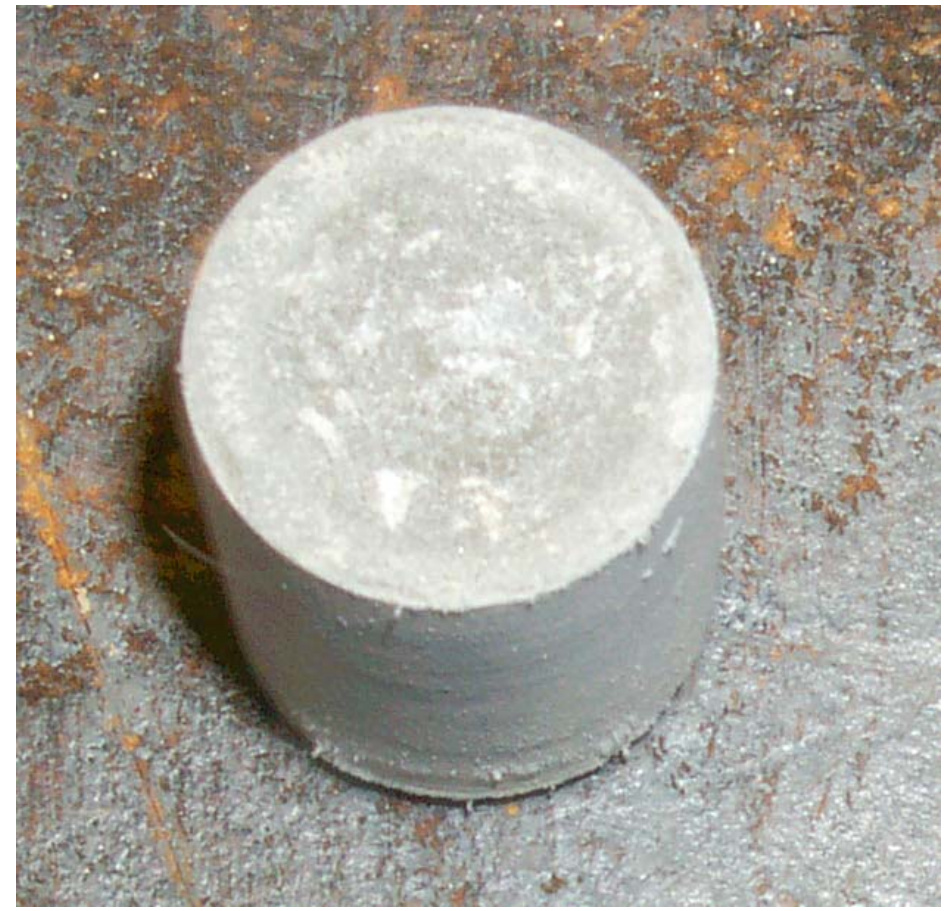

Figure 2. Photograph of the core extracted in Experiment 1 where the rock matrix was saturated, but the fracture was dry. Frost on the surface is caused by matrix water that was driven out while coring or condensation from the air. The core has a one-inch diameter. 


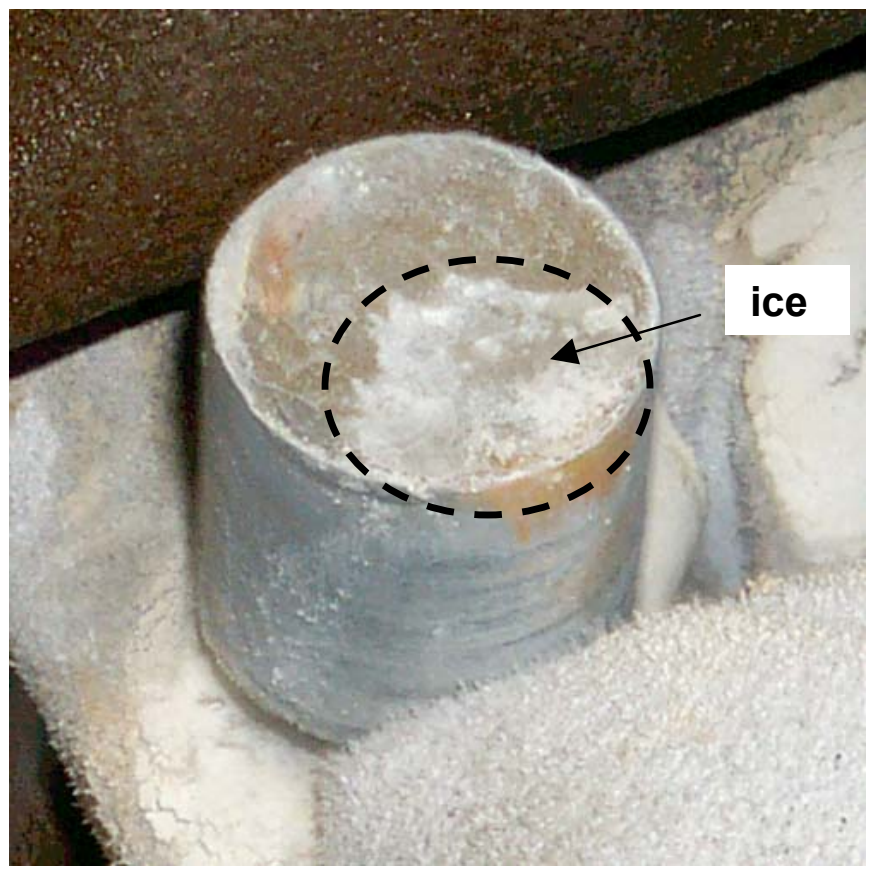

(a) Experiment 2

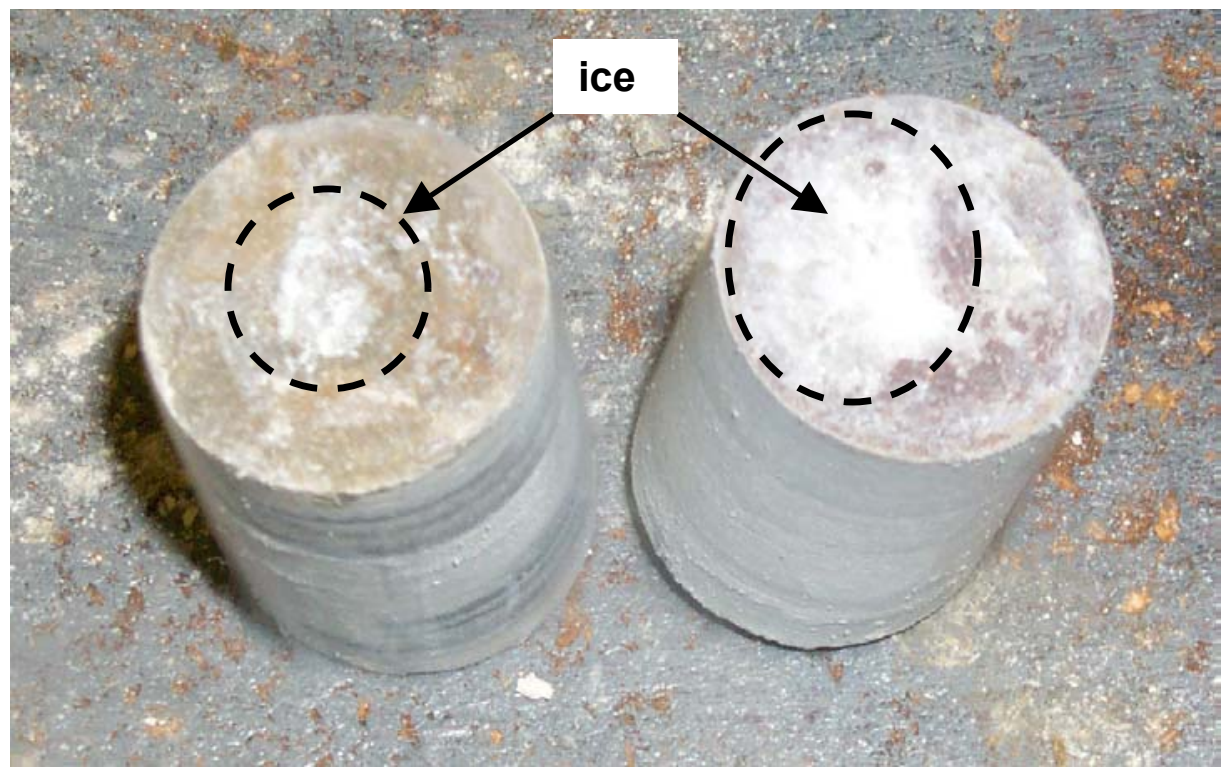

(b) Experiment 3

Figure 3. Photographs of cores extracted in Experiments 2 and 3 where the rock matrix was saturated and the fracture was partially saturated. Circled regions show evidence of ice due to the fracture water freezing while coring. The cores have a one-inch diameter. 